\title{
Ultrasmall NiFe layered double hydroxide strongly coupled on atomically dispersed FeCo-NC nanoflowers as efficient bifunctional catalyst for rechargeable $\mathrm{Zn}$-air battery
}

\author{
Yiyan Wang ${ }^{1}$, Guoxin Zhang ${ }^{2 *}$, Mang Ma ${ }^{1}$, Yan $\mathrm{Ma}^{1}$, Jiankun Huang ${ }^{1}$, Chen Chen ${ }^{1}$, Ying Zhang ${ }^{1}$,
} Xiaoming Sun ${ }^{1}$ and Zifeng Yan ${ }^{1 *}$

\begin{abstract}
An atomically dispersed FeCo-NC material with the 3D flower-like morphology was used as a unique substrate for the controllable deposition of ultrasmall NiFe layered double hydroxide nanodots (termed as NiFe-NDs) to simultaneously promote the sluggish kinetics of oxygen reduction reaction (ORR) and oxygen evolution reaction (OER). The size-limiting growth of NiFe-NDs $(\sim 4.0 \mathrm{~nm}$ in diameter) was realized via the confinement of the 3D flower-like mesoporous structure and the rich N/O functionality of FeCo-NC. Benefiting from the distinctive structure with the simultaneously maximum exposure of both OER and ORR active sites, the NiFe-ND/FeCo-NC composite showed an ORR halfwave potential of $0.85 \mathrm{~V}$ and an OER potential of $1.66 \mathrm{~V}$ in $0.1 \mathrm{~mol} \mathrm{~L}^{-1} \mathrm{KOH}$ at $10.0 \mathrm{~mA} \mathrm{~cm}{ }^{-2}$. In-situ Raman analysis suggested the activity of OER was derived from the $\mathrm{Ni}$ sites on $\mathrm{NiFe-ND/FeCo-NC.} \mathrm{Moreover,} \mathrm{the} \mathrm{NiFe-ND/FeCo-NC-as-}$ sembled $\mathrm{Zn}$-air battery (ZAB) exhibited a very small discharge-charge voltage gap of $0.87 \mathrm{~V}$ at $20 \mathrm{~mA} \mathrm{~cm}$ and robust cycling stability. Furthermore, the NiFe-ND/FeCo-NC composite was also applicable for fabricating all-solid-state ZAB to power wearable electronics with superior cycling stability under deformation. Our work could enlighten a new applicable branch of atomically dispersed metal-nitrogen-carbon materials as unique substrates for fabricating multifunctional electrocatalysts.
\end{abstract}

Keywords: atomically dispersed catalyst, $\mathrm{NiFe}$ layered double hydroxide, oxygen electrocatalyst, bifunctionality, zinc-air battery

\section{INTRODUCTION}

Carbon-based composites are a typical family of functional materials for electrochemical applications due to their low costs, high adjustibility, high conductivity and compatibility with the secondary metallic components [1-5]. Carbon materials such as graphene/carbon nanotube (CNT) oxide, reduced/heteroatom-doped graphene/ $\mathrm{CNT}$ oxide, and synthetic heteroatom-doped carbon are the most commonly used substrates for depositing metallic compounds [6-12]. In most cases, they act as templates or conductive substrates $[13,14]$, while a few of them have been developed as co-catalysts [15-17]. Nowadays, integrating active components into delicately designed composites to enable multifunctionality and improve the utilization of both substrates and secondary components is an emerging trend [18], whcih is mainly credited by the developed synthetic technologies for carbon materials with atomic dopants. Normally, the atomic metal dopants are much more active than their non-metal counterparts due to their features of highly unsaturated coordination and strong metal-substrate interactions [2,19-21].

Currently, it is still rare to apply the newly developed atomically dispersed metal-nitrogen carbon (MNC) materials as substrates to support secondary catalytic components especially for the promotion of closely paired electrochemical reactions that demand largely different surface properties. For instance, the paired oxygen reduction reaction (ORR) and oxygen evolution reaction (OER) in aqueous metal-air batteries are theoretically reversible with $\mathrm{O}_{2} / \mathrm{OH}^{-}$conversions, but involve converse

\footnotetext{
${ }^{1}$ State Key Laboratory of Heavy Oil Processing, China University of Petroleum (East China), Qingdao 266580, China

${ }^{2}$ Department of Electrical Engineering and Automation, Shandong University of Science and Technology, Qingdao 266590, China

* Corresponding authors (emails: zfyancat@upc.edu.cn (Yan Z); zhanggx@sdust.edu.cn (Zhang G))
} 
processes: ORR is gas-intaking and OER is gas-evolving, demanding catalysts to be hydrophobic and hydrophilic, respectively [22-24]. Consequently, most ORR catalysts require annealing while that of OER does not [25-27]. Many types of non-precious metal-based catalysts have been investigated to promote ORR and OER [28], among which, the atomically dispersed MNC and layered double hydroxides (LDH) represent two typical sorts of electrocatalysts for ORR and OER, respectively [2,20,21,9-31]. For instance, atomically dispersed Fe-NC, obtained via high-temperature treatments, exhibited extraordinary ORR performance showing half-wave potentials of $0.90 \mathrm{~V}$ which surpassed the commercially available $\mathrm{Pt} / \mathrm{C}$ catalyst $(58 \mathrm{mV})$ [2,25]; however, Fe-NC materials normally showed sluggish OER activity, making them not applicable as OER catalysts. On the contrary, the NiFe-LDH materials are normally synthesized at room temperature and exhibit extraordinarily low overpotentials in the range of 200-300 $\mathrm{mV}$, and yet unfortunately they are not suitable for ORR due to insufficient conductivity and inappropriate surface wettability [26]. Therefore, efficient compositing of typical ORR-active components (such as atomically dispersed MNC) and OER-active components (such as NiFe-LDH) to achieve satisfactory bifunctionality for oxygen electrocatalysis and downstream alkaline metal-air batteries remains challenging [30].

In this work, ultrasmall $\mathrm{NiFe}-\mathrm{LDH}$ nanodots (NiFeNDs) were strongly coupled with a three-dimensional (3D) flower-like atomically dispersed FeCo-NC material and utilized as highly efficient catalyst to simultaneously promote the paired ORR/OER. The atomically dispersed FeCo-NC substrate was synthesized after modification on our previously reported method [21], possessing multiple features of 3D flower-like structure, large specific surface area, high N/Fe/Co contents, and excellent ORR performance. The 3D flower-like structure and N/O functionalities of FeCo-NC played critical roles in the size-limiting growth of NiFe-NDs. X-ray photoelectron spectroscopy (XPS) analyses revealed that the $\mathrm{NiFe-NDs}$ were controllably deposited on the N/O-containing sites rather than FeCo- $\mathrm{N}_{x}$ sites. The as-prepared composite, denoted as $\mathrm{NiFe}-\mathrm{ND} / \mathrm{FeCo}-\mathrm{NC}$, exhibited excellent bifunctional ORR and OER performance by showing an ORR halfwave potential of $0.85 \mathrm{~V}$ and an OER potential of $1.66 \mathrm{~V}$ at $j=10 \mathrm{~mA} \mathrm{~cm}^{-2}$, rendering $\mathrm{NiFe-ND/FeCo-NC}$ as promising candidate for alkaline rechargeable metal-air batteries. Besides, the NiFe-ND/FeCo-NC-assembled Zn-air battery $(\mathrm{ZAB})$ delivered an impressive power density and cycle life, confirming the excellent bifunctional performance and strong coupling interaction between the $\mathrm{NiFe}$ -
NDs and FeCo-NC substrate. Impressively, when integrated into a all-solid-state $\mathrm{ZAB}$, the NiFe-ND/FeCoNC also showed a high open-circuit voltage $(1.412 \mathrm{~V})$, low charge-discharge gap, and excellent cycling durability under alternately folding and releasing, suggesting its promising application in wearable electronics.

\section{EXPERIMENTAL SECTION}

\section{Materials}

Cobaltous chloride $\left(\mathrm{CoCl}_{2}\right)$, ferric chloride $\left(\mathrm{FeCl}_{3}\right)$, zinc chloride $\left(\mathrm{ZnCl}_{2}\right)$, and zinc acetate $\left(\mathrm{Zn}(\mathrm{OAc})_{2}\right)$ were purchased from Aladdin Reagent Co., LTD. Formamide (FA) was purchased from Xilong Chemical Co., Ltd. Ferric nitrate nonahydrate $\left(\mathrm{Fe}\left(\mathrm{NO}_{3}\right)_{3} \cdot 9 \mathrm{H}_{2} \mathrm{O}\right)$, nickel nitrate hexahydrate $\left(\left(\mathrm{Ni}\left(\mathrm{NO}_{3}\right)_{2} \cdot 6 \mathrm{H}_{2} \mathrm{O}\right)\right.$, sodium hydroxide $(\mathrm{NaOH})$, sodium carbonate $\left(\mathrm{Na}_{2} \mathrm{CO}_{3}\right)$ were purchased from Sinopharm Chemical Reagent Co., Ltd. The commercial $\mathrm{RuO}_{2}$ and Pt/C catalyst (20 wt.\%, $3 \mathrm{~nm}$ Pt nanoparticles on Vulcan XC-72 carbon support) were purchased from Sigma-Aldrich Co., LTD. All chemicals were analytical reagent grade (AR grade) and used as received without further purification.

\section{Preparation methods}

\section{Synthesis of atomically dispersed $\mathrm{FeCo}-\mathrm{NC}$}

The precursors for atomically dispersed FeCo-NC was synthesized according to a previous report [21], with the synthetic method described in brief below. Anhydrous

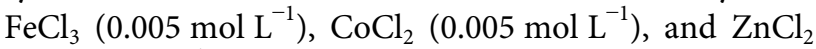
$\left(0.090 \mathrm{~mol} \mathrm{~L}^{-1}\right)$ in $30 \mathrm{~mL} \mathrm{FA}$ were sonicated for $30 \mathrm{~min}$ to form a homogeneous solution at room temperature. Then the uniform solution was transferred into a $50 \mathrm{~mL}$-packed Teflon-lined stainless autoclave and heated at $180^{\circ} \mathrm{C}$ for $12 \mathrm{~h}$. The resulting black product was collected by centrifugation, washed with deionized water and ethanol for thrice, respectively, and dried in oven at $80^{\circ} \mathrm{C}$ for $6 \mathrm{~h}$. In the subsequent pyrolysis procedure, the dried precursor was placed in a porcelain boat and then placed into a flow-through tube furnace, kept at $900^{\circ} \mathrm{C}$ for $1 \mathrm{~h}$ with a heating rate of $5^{\circ} \mathrm{C} \mathrm{min}{ }^{-1}$ under nitrogen atmosphere. After being naturally cooled to room temperature, the typical FeCo-NC was obtained, the as-obtained sample was used without any further treatment.

\section{Synthesis of $\mathrm{NiFe}-\mathrm{ND} / \mathrm{FeCo}-\mathrm{NC}$ composite}

The NiFe-ND/FeCo-NC was prepared by a precipitation method. Firstly, $50 \mathrm{~mL}$ of solution composed of 
$\mathrm{Fe}\left(\mathrm{NO}_{3}\right)_{3} \cdot 9 \mathrm{H}_{2} \mathrm{O}(8.1 \mathrm{mg})$ and $\mathrm{Ni}\left(\mathrm{NO}_{3}\right)_{2} \cdot 6 \mathrm{H}_{2} \mathrm{O}(8.7 \mathrm{mg})$ was added dropwise to the dispersed FeCo-NC $(100 \mathrm{mg})$ in $100 \mathrm{~mL}$ deionized water with ultrasonic treatment at room temperature $\left(25^{\circ} \mathrm{C}\right)$. Then the aqueous solution containing $\mathrm{NaOH} \quad\left(0.15 \mathrm{~mol} \mathrm{~L}^{-1}\right)$ and $\mathrm{Na}_{2} \mathrm{CO}_{3}$ $\left(0.15 \mathrm{~mol} \mathrm{~L}^{-1}\right)$ was added drop by drop to maintain the $\mathrm{pH}$ value of the system at ca. 8 . After magnetic stirring for $12 \mathrm{~h}$ at room temperature $\left(25^{\circ} \mathrm{C}\right)$, the solution was centrifuged at $5000 \mathrm{rpm}$ and washed with deionized water and ethanol for thrice. The NiFe-ND/FeCo-NC was obtained after drying for $6 \mathrm{~h}$ at $60^{\circ} \mathrm{C}$, with a FeCo-NC:NiFe$\mathrm{ND} / \mathrm{FeCo}-\mathrm{NC}$ weight ratio of $\sim 4: 5$. Reference NiFe-LDH sample was prepared under identical conditions to NiFe$\mathrm{ND} / \mathrm{FeCo}-\mathrm{NC}$, but without adding the FeCo-NC.

\section{Characterizations}

The crystal structures of the samples were analyzed by powder X-ray diffraction (X' pert PRO MPD, PANalytical, Almelo, the Netherlands) with $\mathrm{Cu} \mathrm{Ka}$ radiation $(\lambda=1.5418 \AA)$. The morphologies of the samples were observed by field-emission scanning electron microscopy (SEM, JSM-7900F, JEOL, Japan) and high-resolution transmission electron microscopy (HRTEM, JEM2100UHR, JEOL, Japan) equipped with an energy dispersive X-ray spectroscopy (EDS). XPS (ESCALAB 250, Thermo Fisher Scientific, USA) with an Al Ka X-ray source was used to study the surface chemical composition and valence state of the elements. The single atom catalysts were characterized by high-angle annular darkfield scanning TEM (HAADF-STEM) using a scanning/ transmission electron microscope (Titan 80-300, FEI, USA), equipped with a probe spherical aberration corrector. Raman spectra were recorded using a Raman spectrometer (DXR2, Thermofisher, USA) at excitation laser wavelength of $532 \mathrm{~nm}$. Nitrogen adsorption/desorption analyses were performed at $77 \mathrm{~K}$ using a surface analyzer (ASAP 2460, Micromeritics, USA). Prior to the measurement, the samples were degassed at $300^{\circ} \mathrm{C}$. The specific surface areas (SSAs) of the samples were calculated according to the Brunauer-Emmett-Teller (BET) method. The pore size distribution plot was made by applying the Barrett-Joyner-Halenda (BJH) method on the adsorption branch. The bubble contact angle (BCA) was measured by the captive bubble method underwater and the behaviors of bubbles were recorded by a microscope (SZX 16, OLYMPUS) mounted on a high-speed CCD camera (i-SPEED3, AOS Technologies). The resulting catalyst was uniformly dispersed onto the carbon paper and the illumination was achieved by a fiber opticilluminator system (CEL-TCX 250).

\section{Electrochemical evaluation}

All the electrochemical measurements were carried out in a standard three-electrode setup on an electrochemical workstation (760E, $\mathrm{CH}$ Instruments, Shanghai) using a rotating disk electrode (RDE, Pine Research Instrumentation) at room temperature $\left(25^{\circ} \mathrm{C}\right)$. The $\mathrm{Pt}$ electrode, saturated calomel electrode (SCE), and polished glassy carbon (GC) electrode $\left(S \sim 0.196 \mathrm{~cm}^{2}\right)$ were employed as the counter electrode, reference electrode, and the substrate for the working electrode, respectively. For the preparation of the working electrode, $5.0 \mathrm{mg}$ of the catalyst was dispersed in a mixed solution containing $500 \mu \mathrm{L}$ of ethanol and $10 \mu \mathrm{L}$ of Nafion (DuPont, $5.0 \mathrm{wt} . \%)$ solution with the assistance of sonication for at least $1 \mathrm{~h}$. Then, the ink was loaded onto the surface of GC and dried at room temperature with $\sim 0.20 \mathrm{mg} \mathrm{cm}^{-2}$ catalyst loading for all samples. The commercial $20 \mathrm{wt} . \% \mathrm{Pt} /$ $\mathrm{C}$ ink and $\mathrm{RuO}_{2}$ ink were prepared under the same protocol. All electrochemical measurements including cyclic voltammograms (CVs), linear sweep voltammetry (LSV), electrochemical impedance spectroscopy (EIS) and chronoamperometry were performed in $0.1 \mathrm{~mol} \mathrm{~L}^{-1} \mathrm{KOH}$ aqueous solution ( $\mathrm{pH} 12.8$ ) at room temperature. Prior to the test, the electrolyte was pre-saturated with high-purity $\mathrm{N}_{2}$ or $\mathrm{O}_{2}$ flow for at least $30 \mathrm{~min}$, and a constant gas flow was kept during the measurements. The potentials versus the SCE were converted to the reversible hydrogen electrode (RHE) scale based on the following Nernst equation

$E_{\mathrm{RHE}}=E_{\mathrm{SCE}}+0.0591 \times \mathrm{pH}+0.241$.

For ORR measurements, CV curves were collected at the scan rate of $40 \mathrm{mV} \mathrm{s}^{-1}$, and LSVs were recorded at a scan rate of $5 \mathrm{mV} \mathrm{s}^{-1}$. Chronoamperometry tests were conducted in $\mathrm{O}_{2}$-saturated $0.1 \mathrm{~mol} \mathrm{~L}^{-1} \mathrm{KOH}$ at $0.55 \mathrm{~V}(v s$. RHE) with a rotation rate of $1600 \mathrm{rpm}$. The electron transfer number ( $n$ ) was calculated by the Koutecky-Levich equation (2) and (3) as follows

$\frac{1}{J}=\frac{1}{J_{\mathrm{L}}}+\frac{1}{J_{\mathrm{K}}}=\frac{1}{B \omega^{\frac{1}{2}}}+\frac{1}{J_{\mathrm{K}}}$

$B=0.2 n F C_{\mathrm{O}_{2}} D_{\mathrm{O}_{2}}^{\frac{2}{3}} v^{-\frac{1}{6}}$

where $J, J_{\mathrm{L}}$ and $J_{\mathrm{k}}$ are the measured current density, limiting current density and kinetic current density, respectively. $\omega$ is the angular velocity of the disk, $n$ is the electron transfer number. $F\left(96,485 \mathrm{C} \mathrm{mol}^{-1}\right), \quad C_{\mathrm{O}_{2}}$ $\left(1.2 \times 10^{-6} \mathrm{~mol} \mathrm{~cm}^{-3}\right)$ and $D_{\mathrm{O}_{2}}\left(1.9 \times 10^{-5} \mathrm{~cm}^{2} \mathrm{~s}^{-1}\right)$ are the Faraday constant, the bulk concentration of $\mathrm{O}_{2}$, and the diffusion coefficient of $\mathrm{O}_{2}$ in $0.1 \mathrm{~mol} \mathrm{~L}^{-1} \mathrm{KOH}$, respectively. $v\left(0.01 \mathrm{~cm}^{2} \mathrm{~s}^{-1}\right)$ is the kinematic viscosity of the 
electrolyte. The constant of 0.2 is employed when the rotation rate is expressed in $\mathrm{rpm}$.

\section{Liquid ZAB assembly}

The rechargeable liquid $\mathrm{ZAB}$ measurements were assembled with a custom mold. For fabrication of the gasdiffusion cathode, the catalyst ink with a certain volume was coated on the carbon paper and then dried at room temperature. Polished $\mathrm{Zn}$ foil was used as the anode. The gas diffusion area was controlled at $1.0 \mathrm{~cm}^{2}$ to allow $\mathrm{O}_{2}$ penetration. The catalyst loading was about $1.0 \mathrm{mg} \mathrm{cm}^{-2}$ and $6.0 \mathrm{~mol} \mathrm{~L}^{-1} \mathrm{KOH}$ aqueous solution containing $0.2 \mathrm{~mol} \mathrm{~L}^{-1} \mathrm{Zn}(\mathrm{OAc})_{2}$ was used as the electrolyte. The long-term cycling test was carried out with 10-min charging and 10-min discharging at different current densities by using a Land-CT2001A testing system. The red light-emitting diodes (LED, $2.7 \mathrm{~V}$ ) panel is commercially available.

\section{Flexible solid-state $\mathrm{ZAB}$ assembly}

The fexiable solid-state ZAB was fabricated in a sandwich structure. The outermost layer air cathode was fabricated by dropping a certain volume of catalyst ink onto a cleaned carbon cloth $\left(2 \times 2.5 \mathrm{~cm}^{2}\right.$, W1S 1005, CeTech $)$ with a catalyst loading of $1 \mathrm{mg} \mathrm{cm}^{-2}$. The solid electrolyte was prepared as follows: $1 \mathrm{~g}$ polyvinly acetate (PVA) powder (molecular weight $\sim 195,000$ ) was dissolved in $10.0 \mathrm{~mL}$ deionized water at $95^{\circ} \mathrm{C}$ for $2 \mathrm{~h}$ with continous stirrng. Then $1.0 \mathrm{~mL}$ of $18.0 \mathrm{~mol} \mathrm{~L}^{-1} \mathrm{KOH}$ containing $0.02 \mathrm{~mol} \mathrm{~L}^{-1}$ zinc acetate was added dropwise. After being stirred for $0.5 \mathrm{~h}$, the transparent gel was poured into a container and freezed at $-20^{\circ} \mathrm{C}$ for $2 \mathrm{~h}$. The solid electrolyte was obtained after thawing at room temperature.
Then the air electrode was directly coated on the surface of the electrolyte wrapped $\mathrm{Zn}$-spring anode. The test for the wearable $\mathrm{ZAB}$ was performed using recurrent galvanostatic pulses for 5-min of discharge followed by 5 -min of charge. The red LED light $(1.7 \mathrm{~V})$ is commercially available.

\section{RESULTS AND DISCUSSION}

The synthesis of $\mathrm{NiFe}-\mathrm{ND} / \mathrm{FeCo}-\mathrm{NC}$ composite is illustrated in Scheme 1. The atomically dispersed FeCo-NC material was firstly obtained via stepwise solvothermal treatment/pyrolysis by modifying our previous method [21], with heavily loaded $\mathrm{N}$ species and atomically dispersed $\mathrm{Fe}$ and Co components in the N-doped carbon materials, and 3D flower-like mesoporous structure (Fig. 1a). As shown in Fig. 1b, no obvious particulate metal aggregates are in FeCo-NC. HAADF-STEM confirms the atomic dispersion of $\mathrm{Fe} / \mathrm{Co}$ components in FeCo-NC, as indicated by the dense isolated bright dots in Fig. 1c. The 3D flower-like mesoporous structure and rich $\mathrm{N} / \mathrm{O}$ functionality can benefit the confinement of ion adsorption and tunable nucleation of NiFe-NDs [13].

To obtain strongly coupled NiFe-ND/FeCo-NC composite, FeCo-NC was suspended in $\mathrm{Ni}^{2+} / \mathrm{Fe}^{3+}$ solution, and afterwards, the NiFe-NDs were in-situ grown on the FeCo-NC upon the dropwise addition of alkaline solution. As revealed in Fig. 1d, e, the NiFe-NDs are decorated on the petals of flower-like FeCo-NC. The particlesize histogram was drawn based on 50 nanodots (Fig. 1e, inset), and the average diameter was calculated to be $3.7 \mathrm{~nm}$ based on the Gaussian distribution result. Whereas the directly prepared NiFe-LDH without FeCoNC substrate shows bulk stacking structure (Fig. S1),

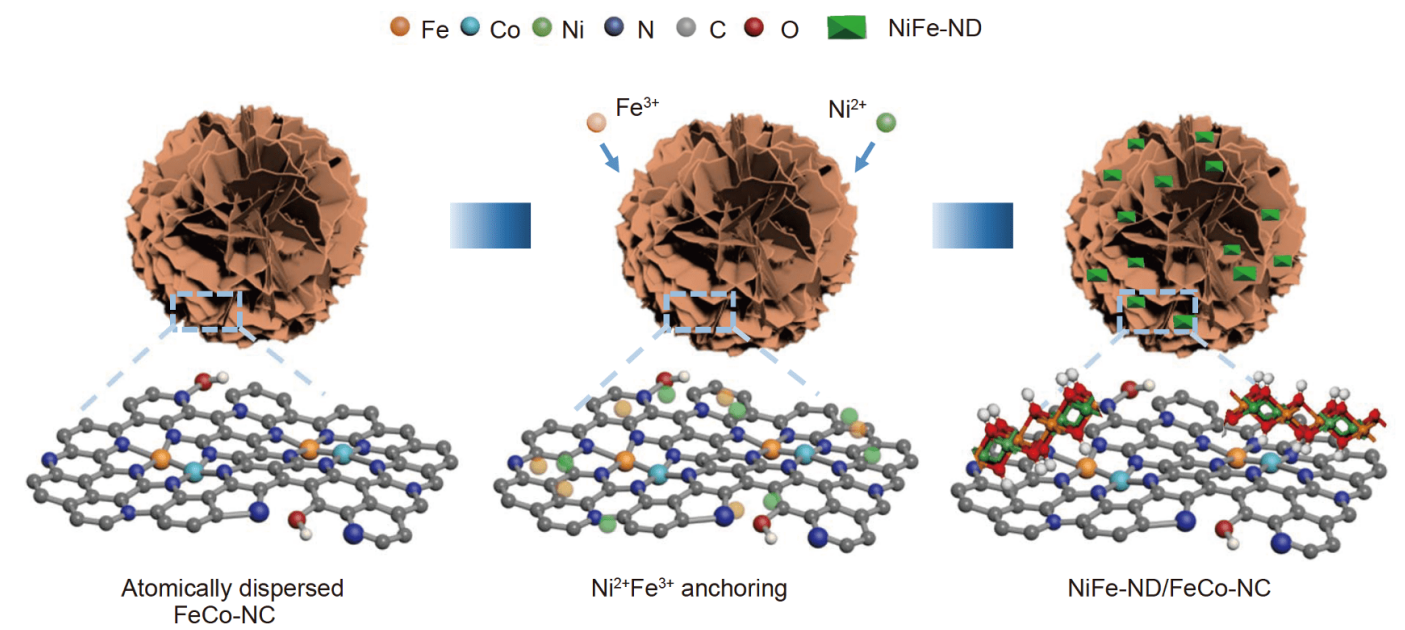

Scheme 1 Schematic diagram for preparing the NiFe-ND/FeCo-NC composite. 

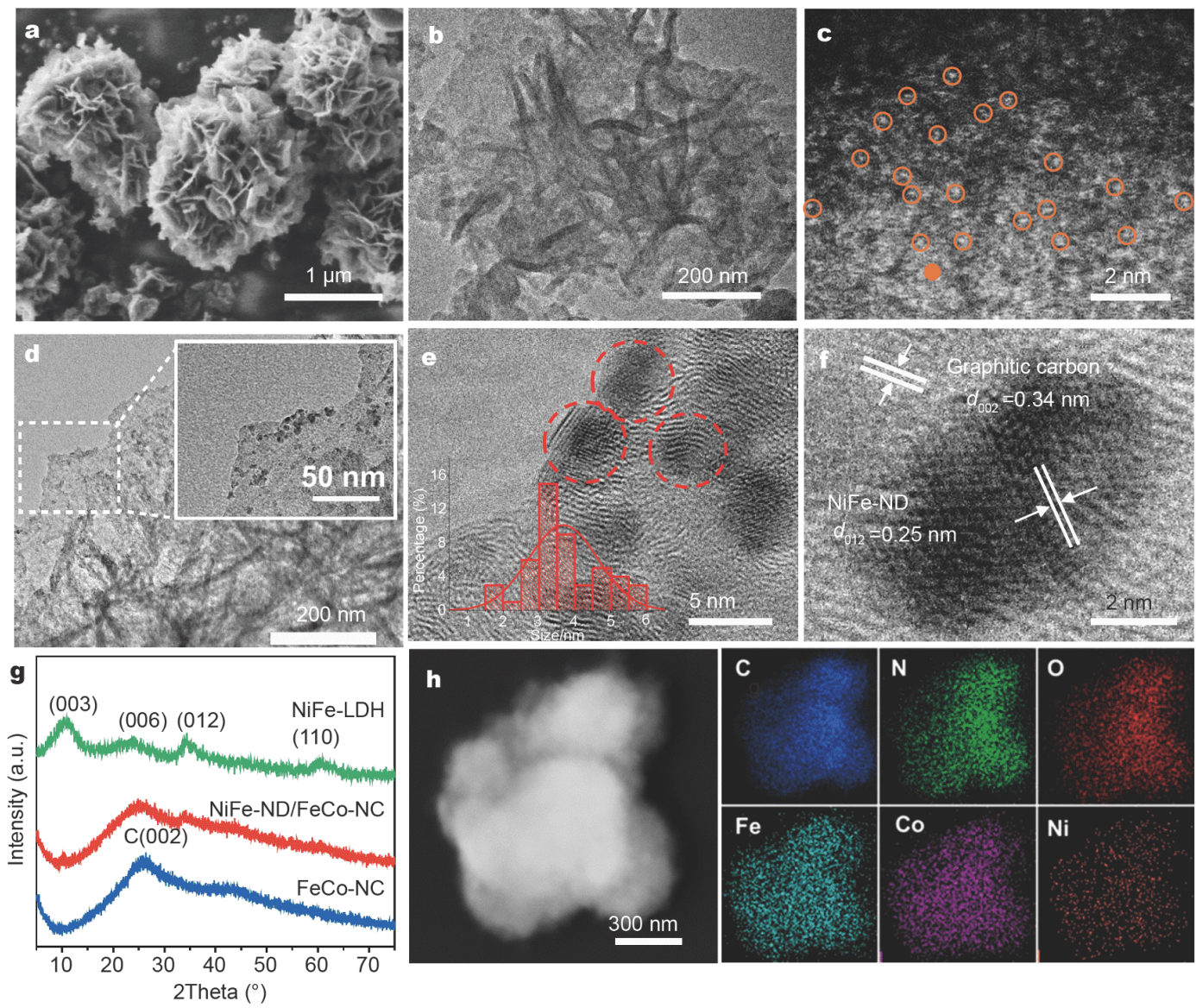

Figure 1 (a) SEM, (b) TEM, and (c) HADDF-STEM images of the atomically dispersed FeCo-NC. (d-f) HRTEM images of the NiFe-ND/FeCo-NC composite. The inset in panel (e) shows the size histogram of nanodots diameters. (g) XRD patterns of FeCo-NC, NiFe-ND/FeCo-NC, and reference sample NiFe-LDH. (h) Dark-field TEM image and corresponding element mapping images of NiFe-ND/FeCo-NC.

confirming the critical role of FeCo-NC in the size-limiting growth of NiFe-NDs. HRTEM (Fig. 1f) reveals that the fringe spacing of NiFe-NDs is $\sim 0.25 \mathrm{~nm}$, which is consistent with the (012) lattice spacing of NiFe-LDH [32], confirming the formation of NiFe-NDs on FeCoNC. The broad peak at around $26.5^{\circ}$ can be assigned to the (002) reflection of graphitic carbon in FeCo-NC [21], with no metallic component for FeCo-NC (Fig. 1g). A new set of hydrotalcite-like characteristic (003), (006), (012), and (110) peaks for NiFe-LDH are consistent with previous literatures [33].

The dark-field TEM and EDS mapping results in Fig. $1 \mathrm{~h}$ indicate the homogeneous distribution of $\mathrm{Ni}, \mathrm{Fe}$, $\mathrm{Co}, \mathrm{C}, \mathrm{O}$ and $\mathrm{N}$, implying the uniform growth and high dispersion of $\mathrm{NiFe}-\mathrm{NDs}$ on the atomically dispersed FeCo-NC substrate. Besides, the SEM image in Fig. S2 further confirms that the morphology of FeCo-NC is well-kept after grafting NiFe-NDs. Raman spectroscopy
(Fig. 2a) further reveals the typical D and G bands for graphitic carbon in both samples before and after the deposition of NiFe-NDs. The D band $\left(\sim 1360 \mathrm{~cm}^{-1}\right)$ and G band $\left(\sim 1600 \mathrm{~cm}^{-1}\right)$ respectively correspond to the disorder vibration mode of structural defects and the wellordered scattering of graphitic carbon [1,34]. As can be seen, the intensity ratio of the distorted carbon to graphitic carbon $\left(I_{\mathrm{D}} / I_{\mathrm{G}}\right)$ in FeCo-NC is 1.22 , indicating the FeCo-NC contains plenty of structural defects. The alien functionalities especially the $\mathrm{N}$-/O-containing groups can serve as anchoring sites for the adsorption of $\mathrm{Ni}^{2+} / \mathrm{Fe}^{3+}$ and also the fast nucleation sites for NiFe-ND growth, which can enable strongly coupled interfacial junctions [35]. The pore structures of $\mathrm{NiFe}-\mathrm{ND} / \mathrm{FeCo}-\mathrm{NC}$ and FeCo-NC were examined using $\mathrm{N}_{2}$ adsorption-desorption isotherms (Fig. 2b). The typical type-IV isotherm with hysteretic loops indicates the presence of various pore types ranging from meso- to micropores [36]. Further- 
more, the BET SSA of FeCo-NC decreases to 220 from $280 \mathrm{~m}^{2} \mathrm{~g}^{-1}$ after NiFe-ND growth. As indicated by the pore size distribution curves in Fig. $2 \mathrm{~b}$ inset, the NiFeNDs were likely grown in the mesopores, resulting in the decrease of SSA and mesopore volume [37].

XPS measurements were conducted to gain further insight into the elemental composition in the NiFe-ND/ FeCo-NC. As shown in Fig. S3a, the XPS element survey corroborates the co-existance of $\mathrm{Ni}, \mathrm{Fe}, \mathrm{Co}, \mathrm{C}, \mathrm{N}$, and $\mathrm{O}$. Fig. S3b indicates that the total non-metal content in FeCo-NC approaches 99.40 at.\%, and the $\mathrm{Fe}$ and $\mathrm{Co}$ contents are 0.35 and 0.24 at.\%, respectively. The $\mathrm{Ni}$ and $\mathrm{Fe}$ contents in NiFe-LDH/FeCo-NC increase to 2.46 and 1.51 at.\%, respectively. The feature of high $\mathrm{N}$ content in both $\mathrm{NiFe}-\mathrm{ND} / \mathrm{FeCo}-\mathrm{NC}$ and FeCo-NC is also confirmed by the $\mathrm{C} 1 \mathrm{~s}$ spectra and their deconvolution. As shown in Fig. S3d, considerable $\mathrm{C}-\mathrm{N}$ bonding is observed at $285.6 \mathrm{eV}$. Meanwhile, the surface $\mathrm{O}$ content of NiFe-ND/ FeCo-NC increases from 7.31 to 17.77 at.\% after NiFeND growth [34]. The core level N 1s region (Fig. S3c) can be deconvoluted into four types of $\mathrm{N}$ species in both
NiFe-ND/FeCo-NC and FeCo-NC: pyridinic N $(\sim 398.2 \mathrm{eV})$, pyrrolic $\mathrm{N}(\sim 399.3 \mathrm{eV})$, graphitic $\mathrm{N}$ $(\sim 400.5 \mathrm{eV})$ and oxidized $\mathrm{N}(\sim 403.0 \mathrm{eV})$ [38]. The pyridinic $\mathrm{N}$ takes more than $50 \%$ in both $\mathrm{NiFe}-\mathrm{ND} / \mathrm{FeCo}-\mathrm{NC}$ and $\mathrm{FeCo}-\mathrm{NC}$, and the high content of anchorable pyridinic and pyrrolic $\mathrm{N}$ is beneficial for stabilizing more Co and $\mathrm{Fe}$ in isolation state [39].

The high-resolution Ni 2p XPS spectrum of NiFe-ND/ FeCo-NC in Fig. 2c exhibits four main peaks, corresponding to $\mathrm{Ni} 2 \mathrm{p}_{3 / 2}(856.5 \mathrm{eV})$ and Ni $2 \mathrm{p}_{1 / 2}(874.0 \mathrm{eV})$ of $\mathrm{Ni}^{2+}$ and two other shake-up satellites. Interestingly, a $0.6 \mathrm{eV}$ binding energy shift of $\mathrm{Ni} 2 \mathrm{p}$ to higher position is detected for $\mathrm{NiFe}-\mathrm{ND} / \mathrm{FeCo}-\mathrm{NC}$ compared with $\mathrm{NiFe}$ $\mathrm{LDH}$, indicating the $\mathrm{Ni}$ in NiFe-NDs is in electron depletion state after being deposited on FeCo-NC [36]. For Co $2 \mathrm{p}$ spectrum, the characteristic peaks at $\sim 780.8$ and $\sim 795.6 \mathrm{eV}$ in FeCo-NC are ascribed to Co $2 \mathrm{p}_{3 / 2}$ and Co $2 \mathrm{p}_{1 / 2}$, respectively, no obvious variation appears after grafting NiFe-NDs (Fig. $2 \mathrm{~d}$ ), suggesting the NiFe-NDs are probably anchored on the N-/O-containing sites [40]. Similarly, the peaks centered at $\sim 710.4$ and $\sim 712.4 \mathrm{eV}$ are
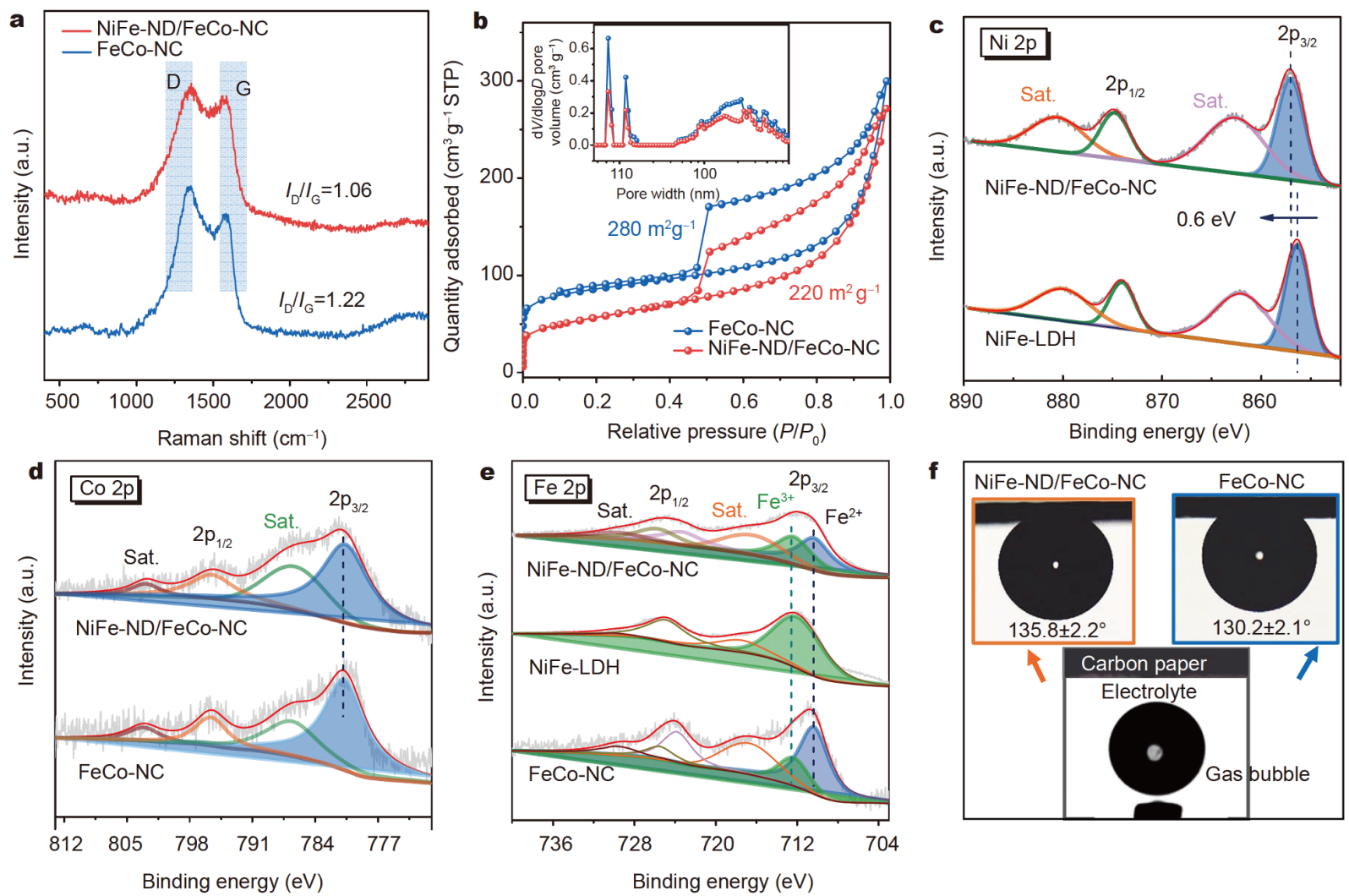

Figure 2 (a) Raman spectra of NiFe-ND/FeCo-NC and FeCo-NC. (b) $\mathrm{N}_{2}$ adsorption/desorption isotherms of FeCo-NC and NiFe-ND/FeCo-NC, the inset shows their pore size distribution curves. (c) High resolution Ni $2 p$ spectra, (d) Co $2 p$ spectra, and (e) Fe 2p spectra of FeCo-NC, NiFe-ND/ FeCo-NC, and NiFe-LDH. (f) Gas BCA measurement of NiFe-ND/FeCo-NC and FeCo-NC under water. 
respectively assigned to the $\mathrm{Fe} 2 \mathrm{p}_{3 / 2}$ of $\mathrm{Fe}^{2+}$ and $\mathrm{Fe}^{3+}$ branches (Fig. 2e) [41,42]. Since Ni and Fe occupy divalent and trivalent cation sites with a ratio of 3:1 in the crystalized $\mathrm{NiFe}-\mathrm{LDH}$, respectively, only trivalent $\mathrm{Fe}^{3+}$ other than $\mathrm{Fe}^{2+}$ is deconvoluted in NiFe-LDH [43]. After NiFe-ND deposition, the $\mathrm{Fe}^{3+} / \mathrm{Fe}^{2+}$ ratio signficantly increases to 0.82 compared with the original FeCo-NC (0.36). The above-confirmed binding energy shifts of $\mathrm{Ni}$ and the significantly altered $\mathrm{Fe}^{3+} / \mathrm{Fe}^{2+}$ ratio confirm the successful loading of NiFe-NDs on FeCo, and strong coupling interaction between the $\mathrm{NiFe}-\mathrm{NDs}$ and $\mathrm{FeCo}-$ $\mathrm{NC}[18,36]$, therefore leading to the $\mathrm{Co}-\mathrm{N}$ and $\mathrm{Fe}-\mathrm{N}$ coordinations in FeCo-NC undisturbed [21]. Besides, BCAs of FeCo-NC before and after loading NiFe-NDs were measured to evaluate their aerophilicitiy $[44,45]$. Digital images in Fig. $2 \mathrm{f}$ show that the NiFe-ND/FeCoNC exhibits a larger BCA of $135.8^{\circ} \pm 2.2^{\circ}$ than that of FeCo-NC $\left(130.2^{\circ} \pm 2.1^{\circ}\right)$, confirming its higher aerophilicitiy, which may benefit the efficient utilization of gaseous oxygen and facilitate high-rate ORR kinetics [46]. While the lower aerophilicitiy of NiFe-ND/FeCo-NC resulted from grafting NiFe-NDs renders reduced adhesion force to $\mathrm{O}_{2}$ bubbles, which could contribute to the OER $[24,47]$.

To further study the electrocatalytic performance of $\mathrm{NiFe}-\mathrm{ND} / \mathrm{FeCo}-\mathrm{NC}$ composite, $\mathrm{CV}$ measurements were initially carried out using a conventional three-electrode setup in $\mathrm{O}_{2}$ - or $\mathrm{N}_{2}$-saturated $0.1 \mathrm{~mol} \mathrm{~L}^{-1} \mathrm{KOH}$ solution. Fig. S4 features FeCo-NC with a typical rectangular double-layer capacitor profile in $\mathrm{N}_{2}$-saturated electrolyte, whereas a well-defined reduction peak centered at $\sim 0.85 \mathrm{~V}$ in $\mathrm{O}_{2}$-saturated $0.1 \mathrm{~mol} \mathrm{~L}^{-1} \mathrm{KOH}$ can be observed, suggesting its pronounced electrocatalytic ORR activity [48]. The performance of $\mathrm{NiFe}-\mathrm{ND} / \mathrm{FeCo}-\mathrm{NC}$ was also evaluated against the individual component based on the LSV with RDE equipment, a mechanical mixture of $\mathrm{NiFe}-\mathrm{LDH}$ and FeCo-NC (denoted as NiFe-LDH+FeCo$\mathrm{NC}$, with weight ratio of $1: 4$ ) and the commercial $\mathrm{Pt} / \mathrm{C}$ catalyst (Fig. 3a). The NiFe-ND/FeCo-NC manifests excellent ORR activity with a high onset potential $\left(E_{\text {onset }}\right)$ and half-wave potential $\left(E_{1 / 2}\right)$ of $\sim 0.93$ and $\sim 0.85 \mathrm{~V}$, respectively, which are comparable to that of $\mathrm{Pt} / \mathrm{C}(\sim 0.94$ and $0.85 \mathrm{~V}$, respectively) and better than that of the mechanical mixture of NiFe-LDH+FeCo-NC ( 0.91 and $0.83 \mathrm{~V}$, respectively), while $\mathrm{NiFe}-\mathrm{LDH}$ exhibits the worst ORR performance [49].

As previously studied by our group, the superior ORR activity of atomically dispersed binary FeCo-NC mainly originated from the cooperative $\mathrm{Fe}\left(\mathrm{N}_{3}\right)-\mathrm{Co}\left(\mathrm{N}_{3}\right)$ sites in the $\mathrm{N}$-doped carbonaceous material [21], and additionally due to the ultrasmall sizes of NiFe-NDs that avoid severely blocking of the $\mathrm{Fe} / \mathrm{Co}$-based active sites [50,51]. $\mathrm{RDE}$ measurements with rotation speeds ranging from 400 to $2025 \mathrm{rpm}$ were conducted to further investigate the ORR reaction kinetics (Fig. $3 \mathrm{~b}$ and Fig. S5). The limiting current density increases with the acceleration of rotation speed, as the oxygen flux diffuses faster to the electrode surface under higher rotation speed [52]. The KouteckyLevich (K-L) curves derived from the corresponding polarization curves at different potentials are further plotted, and reflect good linearity with parallelism from 0.3 to $0.7 \mathrm{~V}$. The electron transfer number $n$ values calculated from the K-L plots indicate $4-\mathrm{e}^{-}$reduction pathways on both NiFe-ND/FeCo-NC and FeCo-NC. Meanwhile, the Tafel slope values calculated using 1600rpm LSV curves are 87, 90, 98, and $92 \mathrm{mV} \mathrm{dec}^{-1}$ for FeCo-NC, NiFe-ND/FeCo-NC, NiFe-LDH+FeCo-NC, and $\mathrm{Pt} / \mathrm{C}$, respectively (Fig. S6), indicating faster kinetics of $\mathrm{NiFe}-\mathrm{ND} / \mathrm{FeCo}-\mathrm{NC}$ compared with the NiFe-LDH $+\mathrm{FeCo}-\mathrm{NC}$ mixture. The improvement of ORR activity could be explained by the strong coupling interaction between the NiFe-NDs and FeCo-NC substrate, as evidenced by the XPS results.

EIS was further conducted, as shown in Fig. $3 c$, the arc in the high-frequency region is related to the chargetransfer resistance $\left(R_{\mathrm{ct}}\right)$ correlating with electrochemical kinetics at the catalyst interface, and the smaller radius is associated with faster mass/electron exchange behavior $[40,53]$. As can be seen, the semicircular diameter of $\mathrm{NiFe}-\mathrm{ND} / \mathrm{FeCo}-\mathrm{NC}$ is smaller compared with that of $\mathrm{NiFe}-\mathrm{LDH}+\mathrm{FeCo}-\mathrm{NC}$, indicating the faster reaction kinetics with a higher electron transfer rate, which is in good agreement with the catalytic activity measured by LSV $[38,43]$. Owing to the high graphitization degree and the 3D flower-like structure of FeCo-NC substrate, the catalysts exhibit very good long-term stability in $\mathrm{O}_{2}$-saturated electrolyte [54], showing limited variation in $E_{\text {onset }}$ and $E_{1 / 2}$, and very high current retention of $91 \%$ after $10,000 \mathrm{~s}$ continuous working at $0.6 \mathrm{~V}$ ( $v s$. RHE), while the commercial $\mathrm{Pt} / \mathrm{C}$ exhibits $23 \%$ current degradation, as compared in Fig. 3d.

Apart from the outstanding ORR activity, the NiFe$\mathrm{ND} / \mathrm{FeCo}-\mathrm{NC}$ also exhibits significantly improved activity towards OER compared with FeCo-NC. As shown in Fig. 3e, the potential required to reach $j=10 \mathrm{~mA} \mathrm{~cm}^{-2}$ for $\mathrm{NiFe}-\mathrm{ND} / \mathrm{FeCo}-\mathrm{NC}$ is $\sim 1.66 \mathrm{~V}$, which is significantly lower than that of FeCo-NC $(\sim 1.80 \mathrm{~V})$ and NiFe-LDH $+\mathrm{FeCo}-\mathrm{NC}(\sim 1.73 \mathrm{~V})$. It should be noted that the redox peaks locating at $\sim 1.5 \mathrm{~V}$ are detectable in NiFe-LDH, $\mathrm{NiFe}-\mathrm{ND} / \mathrm{FeCo}-\mathrm{NC}$, and $\mathrm{NiFe}-\mathrm{LDH}+\mathrm{FeCo}-\mathrm{NC}$, which 

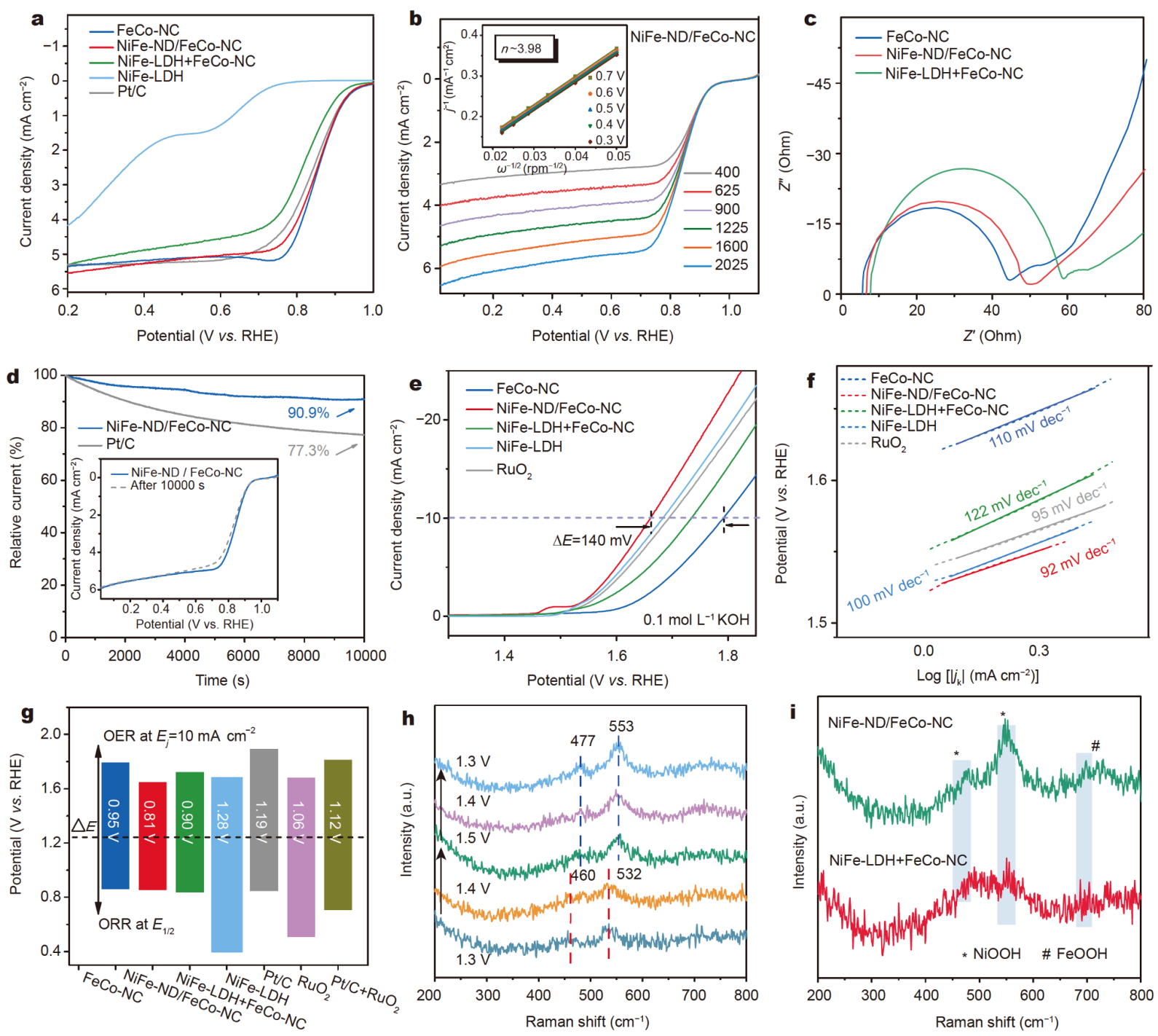

Figure 3 Electrochemical measurements on FeCo-NC, NiFe-ND/FeCo-NC, NiFe-LDH+FeCo-NC, NiFe-LDH, and reference sample (Pt/C and/or $\mathrm{RuO}_{2}$ ): (a) ORR LSV curves, (b) LSV curves of NiFe-ND/FeCo-NC at different rotation speeds (inset shows their corresponding K-L plots). (c) Nyquist plots of the catalysts in $0.1 \mathrm{~mol} \mathrm{~L}^{-1} \mathrm{KOH}$. (d) The durability tests of NiFe-ND/FeCo-NC and reference sample Pt/C. The inset shows the LSV curves before and after durability test for 10,000-second long working at $0.6 \mathrm{~V}$ ( $v$ s. RHE). (e) OER LSV curves and (f) the corresponding Tafel plots. (g) Potential gaps between the ORR $E_{1 / 2}$ (half-wave potential) and the OER at $10 \mathrm{~mA} \mathrm{~cm}{ }^{-2}$. (h) In-situ Raman spectra of NiFe-ND/FeCo-NC at different potentials during anodic and cathodic sweep in a CV cycle and (i) Raman spectra of NiFe-ND/FeCo- $\mathrm{NC}$ and $\mathrm{NiFe}-\mathrm{LDH}+\mathrm{FeCo}-\mathrm{NC}$ at potential=1.5 V ( $v s$. RHE) holding for $10 \mathrm{~min}$.

can be assigned to the $\mathrm{Ni}^{2+} / \mathrm{Ni}^{3+}$ redox reaction. The most obvious redox peak for $\mathrm{NiFe}-\mathrm{ND} / \mathrm{FeCo}-\mathrm{NC}$ suggests its intense charge transfer relating to $\mathrm{Ni}^{2+} / \mathrm{Ni}^{3+}$ transformation [34]. Meanwhile, the corresponding Tafel slope of $\mathrm{NiFe}-\mathrm{ND} / \mathrm{FeCo}-\mathrm{NC}$ is $\sim 92 \mathrm{mV} \mathrm{dec}{ }^{-1}$, lower than those of $\mathrm{NiFe}-\mathrm{LDH}+\mathrm{FeCo}-\mathrm{NC}\left(\sim 122 \mathrm{mV} \mathrm{dec}^{-1}\right)$ and NiFe-LDH $\left(\sim 100 \mathrm{mV} \mathrm{dec}^{-1}\right)$, as shown in Fig. $3 \mathrm{f}$.

Compared with NiFe-LDH and NiFe-LDH+FeCo-NC, the excellent OER activity of NiFe-ND/FeCo-NC composite can be ascribed to the high activity of NiFe-NDs, high conductivity of FeCo-NC substrate and the strong coupling effect between NiFe-NDs and FeCo-NC (Fig. 2c). Besides, the NiFe-NDs anchored on FeCo-NC are expected to expose more active sites compared with bare NiFe-LDH due to nanosize effects [55]. The stability tests reveal that the LSV profile of NiFe-ND/FeCo-NC is retainable after 3000 cycles (Fig. S7a) [34]. Besides, the SEM image reveals that the morphology of the catalyst is well maintained after durability tests (Fig. S7b). Fig. 3g displays the comparison of bifunctional ORR/OER ac- 
tivity of NiFe-ND/FeCo-NC with other materials studied in this work. The NiFe-ND/FeCo-NC exhibits the smallest potential gap $(\Delta E)$ of $0.81 \mathrm{~V}$ between $E_{j 10}$ (the potential at a current density of $10.0 \mathrm{~mA} \mathrm{~cm}^{-2}$ ) and $E_{1 / 2}$ (ORR half-wave potential), which is much smaller than that of $\mathrm{FeCo}-\mathrm{NC}(0.95 \mathrm{~V})$ and $\mathrm{NiFe}-\mathrm{LDH}+\mathrm{FeCo}-\mathrm{NC}$ $(0.90 \mathrm{~V})$.

In-situ Raman analyses were performed to investigate the underneath OER mechanism on NiFe-ND/FeCo-NC by monitoring the distribution of the key reaction intermadiates during OER process, and the digital image of a custom mold in-situ electrochemical cell is shown in Fig. S8. A series of Raman spectra for NiFe-ND/FeCo-NC act as a functional of applied potential during the $\mathrm{CV}$ sweep from 1.3 to $1.5 \mathrm{~V}$ then to $1.3 \mathrm{~V}$, as shown in Fig. $3 \mathrm{~h}$. The peaks at 460 and $532 \mathrm{~cm}^{-1}$ can be assigned to the $\mathrm{Ni}-\mathrm{O}$ vibration mode in NiFe-LDH during the sweep from 1.30 to $1.40 \mathrm{~V}[56,57]$. As the applied potential increases to $1.50 \mathrm{~V}$, where the OER of NiFe-ND/FeCo-NC occurs, the primary two peaks disappear and the pair of new peaks at 477 and $553 \mathrm{~cm}^{-1}$ appear. These two peaks are probably attributed to the characteristic $\mathrm{Ni}-\mathrm{O}$ vibration in $\mathrm{NiOOH}$, indicating the generated oxyhydroxides under the oxygen evolution potential. Meanwhile, the spectral features of NiFe-ND/FeCo-NC and NiFe-LDH $+\mathrm{FeCo}-\mathrm{NC}$ physical mixture were further collected after activation at $1.50 \mathrm{~V}$ for $10 \mathrm{~min}$. As shown in Fig. 3i, a series of peaks assigned to $\mathrm{NiOOH}$ and $\mathrm{FeOOH}$ $\left(\sim 689 \mathrm{~cm}^{-1}\right)$ can be observed. It could be found that the peak relative intensity $I_{553} / I_{477}$ of NiFe-ND/FeCo-NC after activation is higher than that of the physical mixture, indicating that more $\mathrm{NiOOH}$ active sites are generated in $\mathrm{NiFe}-\mathrm{ND} / \mathrm{FeCo}-\mathrm{NC}$, and a stronger peak of $\mathrm{FeOOH}$ appears. The above results clearly evidence that more $\mathrm{Ni}$ and $\mathrm{Fe}$ ions are oxidized to $\mathrm{NiOOH}$ and $\mathrm{FeOOH}$ active sites in $\mathrm{NiFe}-\mathrm{ND} / \mathrm{FeCo}-\mathrm{NC}$ under OER conditions compared with $\mathrm{NiFe}-\mathrm{LDH}+\mathrm{FeCo}-\mathrm{NC}$ physical mixture [58], suggesting the beneficial effect of FeCo-NC substrate. The aforementioned results futher suggest that the $\mathrm{NiFe}-\mathrm{ND} /$ FeCo-NC can serve as efficient non-precious metal bifunctional ORR/OER electrocatalyst for alkaline metal-air batteries.

ZABs were assembled with $\mathrm{NiFe}-\mathrm{ND} / \mathrm{FeCo}-\mathrm{NC}$ as the cathode material to demonstrate its application potentials (Fig. 4a). Reference ZAB cells were also assembled using FeCo-NC, $\mathrm{NiFe}-\mathrm{LDH}+\mathrm{FeCo}-\mathrm{NC}$, and $\mathrm{Pt} / \mathrm{C}+\mathrm{RuO}_{2}$ (with a mass ratio of 1:1). As shown in Fig. $\mathrm{S} 9$, the $\mathrm{ZAB}$ assembled with $\mathrm{NiFe}-\mathrm{ND} / \mathrm{FeCo}-\mathrm{NC}$ exhibits a higher opencircuit voltage $(1.465 \mathrm{~V})$ than that with $\mathrm{NiFe}-\mathrm{LDH}+\mathrm{FeCo}-$ $\mathrm{NC}(1.461 \mathrm{~V})$ and $\mathrm{Pt} / \mathrm{C}+\mathrm{RuO}_{2}(1.455 \mathrm{~V})$, which is very close to that of FeCo-NC (1.470 V). Two NiFe-ND/FeCo$\mathrm{NC}$-assembled ZABs in series manage to power a $2.7 \mathrm{~V}$ LED panel (Fig. 4a). At $10.0 \mathrm{~mA} \mathrm{~cm}^{-2}$, the NiFe-ND/ FeCo-NC composite is able to promote the ZAB device

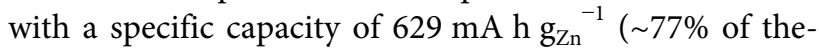
oretical capacity), which is close to that of $\mathrm{FeCo}-\mathrm{NC}$ $\left(650 \mathrm{~mA} \mathrm{~h} \mathrm{~g}_{\mathrm{Zn}}{ }^{-1}\right)$ and outperforms that of NiFe-LDH $+\mathrm{FeCo}-\mathrm{NC}$ mixture ( $600 \mathrm{~mA} \mathrm{~h} \mathrm{~g}_{\mathrm{Zn}}{ }^{-1}$, Fig. $\left.4 \mathrm{~b}\right)$. Fig. $4 \mathrm{c}$ displays the discharge and charge curves of rechargeable $\mathrm{ZAB}$ assembled using different samples with a scan rate of $10 \mathrm{mV} \mathrm{s}^{-1}$. The NiFe-ND/FeCo-NC ZAB shows the lowest charge voltage compared with other catalysts and similarly high discharge voltage as FeCo-NC. The maximum power density of $\mathrm{NiFe}-\mathrm{ND} / \mathrm{FeCo}-\mathrm{NC} \mathrm{ZAB}$ can reach up to $141.0 \mathrm{~mW} \mathrm{~cm}^{-2}$ at $247 \mathrm{~mA} \mathrm{~cm}^{-2}$, which is almost 1.5 times of that using $\mathrm{Pt} / \mathrm{C}+\mathrm{RuO}_{2}$.

The charge-discharge voltage gaps of different samples versus different current densities are summarized in Fig. $4 \mathrm{~d}$. All the samples follow the trend of enlarged chargedischarge voltage gap along with the increase of current density, which is governed by the electrochemical polarization rules [5]. The gap-enlarging rates for different samples show large variations: among all samples, the $\mathrm{NiFe}-\mathrm{ND} / \mathrm{FeCo}-\mathrm{NC}$ shows the least tendency of gap broadening, FeCo-NC and NiFe-LDH+FeCo-NC follow, while $\mathrm{Pt} / \mathrm{C}+\mathrm{RuO}_{2}$ shows the worst capability of maintaining high performance at large current rates. At a high current rate of $20.0 \mathrm{~mA} \mathrm{~cm}^{-2}$, the charge voltage for $\mathrm{Pt} / \mathrm{C}$ $+\mathrm{RuO}_{2}$ increases to $2.30 \mathrm{~V}$ and its discharge voltage touches down to $0.93 \mathrm{~V}$, while the $\mathrm{NiFe}-\mathrm{ND} / \mathrm{FeCo}-\mathrm{NC}$ can still supply a $2.03-\mathrm{V}$ charge plateau and a $1.11-\mathrm{V}$ discharge plateau. Galvanostatic discharge and charge measurements were carried out with selected current densities with 10-min charge/10-min discharge intervals to investigate their long-term cycling stability. At the current density of $5.0 \mathrm{~mA} \mathrm{~cm}^{-2}$, the NiFe-LDH/FeCo$\mathrm{NC}$-assembled ZAB supplies a $1.94-\mathrm{V}$ charge plateau and $1.23-\mathrm{V}$ discharge plateau, delivering a very small voltage gap of $0.71 \mathrm{~V}$ (Fig. S10), which is $40 \mathrm{mV}$ smaller than that of FeCo-NC.

Particularly, the NiFe-ND/FeCo-NC-assembled ZAB possesses superior charge performance compared with both FeCo-NC and NiFe-LDH+FeCo-NC, which can be attributed to the well-dispersed NiFe-NDs on the FeCo$\mathrm{NC}$ support. As shown in Fig. 4e, at large current density of $20.0 \mathrm{~mA} \mathrm{~cm}^{-2}$, the $\mathrm{Pt} / \mathrm{C}+\mathrm{RuO}_{2}$ encounters quick fading after the $30^{\text {th }}$ cycle, while NiFe-ND/FeCo-NC is still able to operate with stable charge/discharge profile for more than 480 cycles and supply a $2.01-\mathrm{V}$ charge plateau and $1.14 \mathrm{~V}$ discharge plateau at $300^{\text {th }}$ cycle. In comparison, 

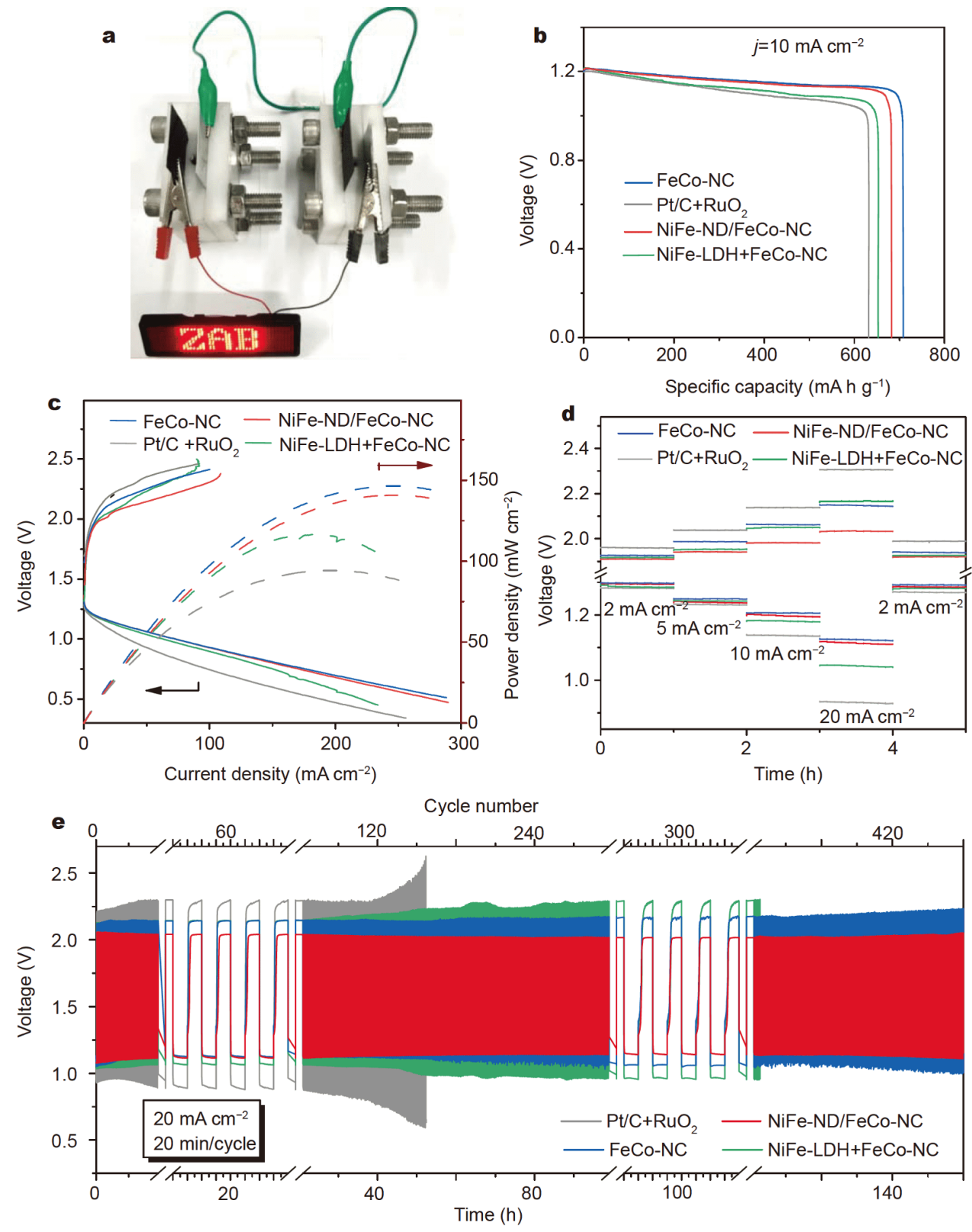

Figure 4 (a) A photograph of LED panel $(2.7 \mathrm{~V}$ ) powered by two series connected NiFe-ND/FeCo-NC-based liquid ZABs. (b) Galvanostatic discharge curves at a current density of $10.0 \mathrm{~mA} \mathrm{~cm}^{-2}$. (c) Polarization curves and power density curves. (d) Charge-discharge voltage gaps versus different current densities. (e) Galvanostatic charge-discharge cycling curves at $20.0 \mathrm{~mA} \mathrm{~cm}^{-2}$.

the $\mathrm{NiFe}-\mathrm{LDH}+\mathrm{FeCo}-\mathrm{NC}$ mixture delivers a continuously enlarged gap and provides a $2.27 \mathrm{~V}$ charge plateau and $0.97-\mathrm{V}$ discharge plateau at the $300^{\text {th }}$ cycle. Table S1 summarizes the performances of ZABs based on NiFe$\mathrm{ND} / \mathrm{FeCo}-\mathrm{NC}$ and other materials studied in this work and the results reported in previous literatures. As compared, the $\mathrm{NiFe}-\mathrm{ND} / \mathrm{FeCo}-\mathrm{NC}$ exhibits very small chargedischarge voltage gap at very large current density of
$20.0 \mathrm{~mA} \mathrm{~cm}^{-2}$, with better durability and stability.

Moreover, to meet the increasing demand for flexible electronics, all-solid state $\mathrm{ZABs}$ were fabricated, as schemed in Fig. $5 \mathrm{a}, \mathrm{NiFe}-\mathrm{ND} / \mathrm{FeCo}-\mathrm{NC}$ is loaded on the carbon cloth and used as the air cathode. Alkaline PVA hydrogel and zinc spring act as the solid-state electrolyte and anode, respectively. As shown in Fig. 5b, c, a high open-circuit potential of $1.412 \mathrm{~V}$ is delivered by using 
a

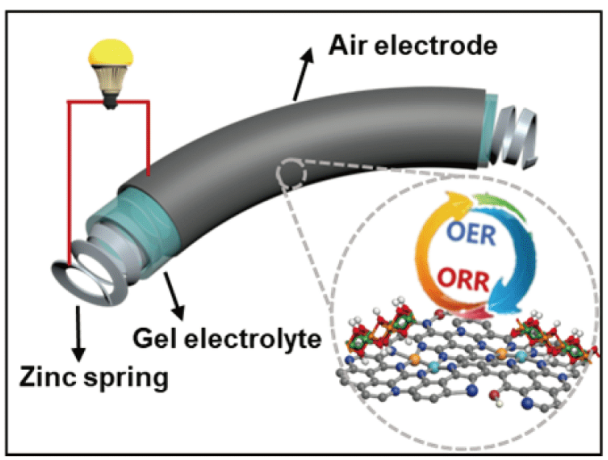

b

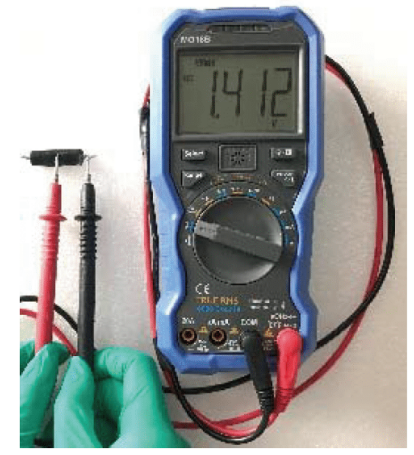

c

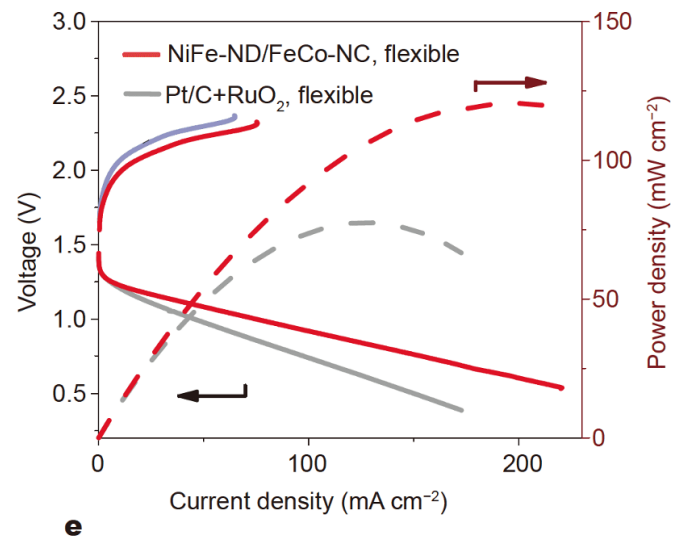

d

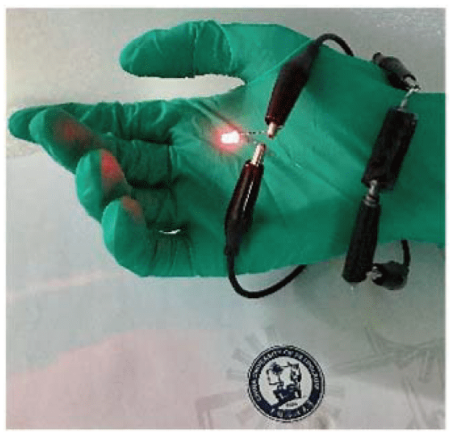

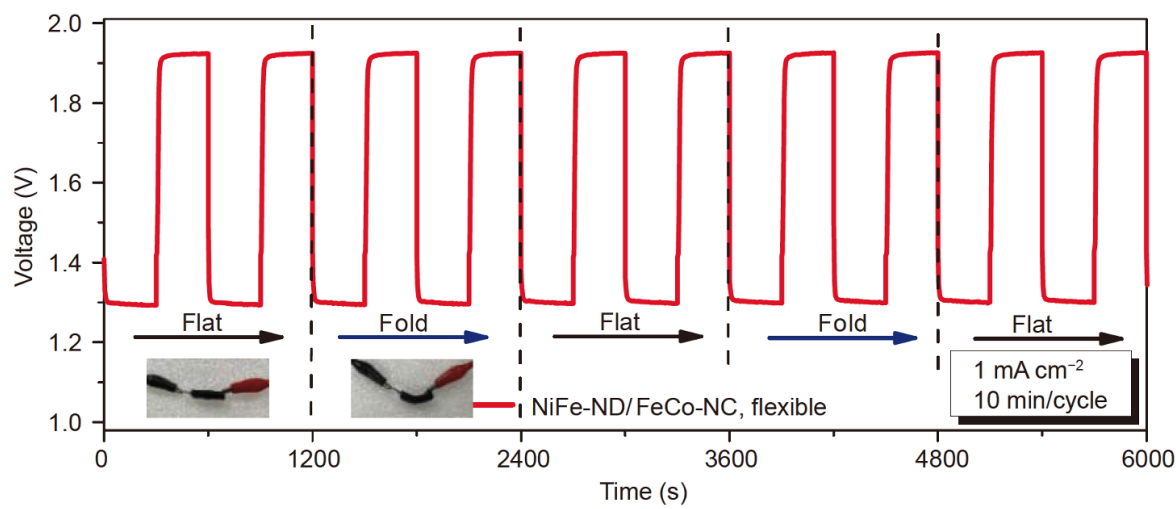

Figure 5 (a) Scheme of a rechargeable solid-state flexible ZAB using NiFe-ND/FeCo-NC as the cathode catalyst. (b) Photograph of the solid ZAB with an open-circuit voltage of $1.412 \mathrm{~V}$. (c) Polarization curves and power density curves of flexible ZABs (10 $\mathrm{mV} \mathrm{s}^{-1}$ scan rate). (d) Digital photo shows the application of wearable ZABs. (e) The charge-discharge curves of the NiFe-ND/FeCo-NC-based solid-state ZAB under alternately folding and releasing conditions.

$\mathrm{NiFe}-\mathrm{ND} / \mathrm{FeCo}-\mathrm{NC}$ as the air cathode, and it also delivers a high maximum power density of $\sim 121.1 \mathrm{~mW} \mathrm{~cm}^{-2}$, outperforming $\mathrm{Pt} / \mathrm{C}-\mathrm{RuO}_{2}\left(\sim 77.6 \mathrm{~mW} \mathrm{~cm}{ }^{-2}\right)$. Meanwhile, the two in-series $\mathrm{NiFe}-\mathrm{ND} / \mathrm{FeCo}-\mathrm{NC}-$ based wearable ZABs assembled using rubber glove as flexible substrate, can continuously light up a commercial red LED light
(Fig. 5d). Typically, the mechanical flexibility and stability tests of NiFe-ND/FeCo-NC-assembled solid-state ZAB were performed by alternately folding $\left(120^{\circ}\right)$ and releasing for every two charge-discharge cycles. As shown in Fig. 5e, with the cycling test carried out for more than $100 \mathrm{~min}$, there is no obvious variation in charge $(\sim 1.93 \mathrm{~V})$ 
and discharge $(\sim 1.28 \mathrm{~V})$ voltage platforms at a current density of $1.0 \mathrm{~mA} \mathrm{~cm}^{-2}$, indicating the robust cycling stability under deformation of the solid-state ZAB.

\section{CONCLUSIONS}

In summary, a feasible approach was developed to design bifunctional electrocatalysts using atomically dispersed MNC as a new type of active substrate. HRTEM reveals that the ultrasmall sized NiFe-NDs are sparsely deposited on the 3D flower-like FeCo-NC, which is critical to avoid the blocking of ORR-active FeCo sites. XPS analyses reveal that the Ni species in NiFe-NDs are more electrondepleted. Taken together, strong coupling interactions between the NiFe-NDs and FeCo-NC substrate are successfully achieved. Electrochemical measurements confirm that the controllable compositing of ultrasmall OERactive NiFe-NDs and ORR-active FeCo-NC substrate render exceptional bifunctional performance towards ORR and OER. Remarkably, the NiFe-ND/FeCo-NC composites exhibit the smallest potential gap of $0.81 \mathrm{~V}$ consisting of a $0.85 \mathrm{~V}$ ORR half-wave potential and a $1.66 \mathrm{~V}$ potential at a current density of $10.0 \mathrm{~mA} \mathrm{~cm}^{-2}$ in $0.1 \mathrm{~mol} \mathrm{~L}^{-1} \mathrm{KOH}$. Meanwhile, under OER conditions, the more $\mathrm{Ni}(\mathrm{Fe}) \mathrm{OOH}$ active sites are observed in $\mathrm{NiFe}-\mathrm{ND} /$ FeCo-NC compared with their physical mixture, further confirming the OER enhancement of FeCo-NC substrate. Moreover, rechargeable liquid-state $\mathrm{ZABs}$ assembled using NiFe-ND/FeCo-NC as cathode possess a very small charge-discharge voltage gap, high rate capability, and highly robust cycling stability. Furthermore, the NiFe$\mathrm{ND} / \mathrm{FeCo}-\mathrm{NC}$ could be applicable for fabricating all-solid-state $\mathrm{ZAB}$ to power wearble electronics, delivering a high open-circuit voltage and a stable charge-discharge voltage platform under repeatedly bending condition. Our work may enlighten the $\mathrm{N}$-doped carbon materials with atomic decoration of metal components as a new type of unique substrate for fabricating integrated composites with multifunctionalities.

\section{Received 12 January 2020; accepted 23 February 2020; published online 7 April 2020}

1 Peng Y, Lu B, Chen S. Carbon-supported single atom catalysts for electrochemical energy conversion and storage. Adv Mater, 2018, 30: 1801995

2 Chen Y, Ji S, Wang Y, et al. Isolated single iron atoms anchored on $\mathrm{N}$-doped porous carbon as an efficient electrocatalyst for the oxygen reduction reaction. Angew Chem Int Ed, 2017, 56: 69376941

3 Shen H, Gracia-Espino E, Ma J, et al. Atomically $\mathrm{FeN}_{2}$ moieties dispersed on mesoporous carbon: A new atomic catalyst for efficient oxygen reduction catalysis. Nano Energy, 2017, 35: 9-16
4 Fei H, Dong J, Feng Y, et al. General synthesis and definitive structural identification of $\mathrm{MN}_{4} \mathrm{C}_{4}$ single-atom catalysts with tunable electrocatalytic activities. Nat Catal, 2018, 1: 63-72

5 Zhang L, Xiao J, Wang H, et al. Carbon-based electrocatalysts for hydrogen and oxygen evolution reactions. ACS Catal, 2017, 7: 7855-7865

6 Zhu Y, Murali S, Cai W, et al. Graphene and graphene oxide: synthesis, properties, and applications. Adv Mater, 2010, 22: 39063924

7 Du Z, Yu P, Wang L, et al. Cubic imidazolate frameworks-derived $\mathrm{CoFe}$ alloy nanoparticles-embedded $\mathrm{N}$-doped graphitic carbon for discharging reaction of Zn-air battery. Sci China Mater, 2020, 63: 327-338

8 Yu L, Yi Q, Yang X, et al. An easy synthesis of Ni-Co doped hollow $\mathrm{C}-\mathrm{N}$ tubular nanocomposites as excellent cathodic catalysts of alkaline and neutral zinc-air batteries. Sci China Mater, 2019, 62: 1251-1264

9 Gong M, Li Y, Wang H, et al. An advanced Ni-Fe layered double hydroxide electrocatalyst for water oxidation. J Am Chem Soc, 2013, 135: 8452-8455

10 Li Y, Gong M, Liang Y, et al. Advanced zinc-air batteries based on high-performance hybrid electrocatalysts. Nat Commun, 2013, 4: 1805

11 Liu X, Wang L, Yu P, et al. A stable bifunctional catalyst for rechargeable zinc-air batteries: iron-cobalt nanoparticles embedded in a nitrogen-doped 3D carbon matrix. Angew Chem, 2018, 130: 16398-16402

12 Wang S, Wang Y, Zhang SL, et al. Supporting ultrathin $\mathrm{ZnIn}_{2} \mathrm{~S}_{4}$ nanosheets on $\mathrm{Co} / \mathrm{N}$-doped graphitic carbon nanocages for efficient photocatalytic $\mathrm{H}_{2}$ generation. Adv Mater, 2019, 31: 1903404

13 Zhao MQ, Zhang Q, Huang JQ, et al. Hierarchical nanocomposites derived from nanocarbons and layered double hydroxides-properties, synthesis, and applications. Adv Funct Mater, 2012, 22: 675694

14 Rao CNR, Sood AK, Subrahmanyam KS, et al. Graphene: The new two-dimensional nanomaterial. Angew Chem Int Ed, 2009, 48: 7752-7777

15 Tang C, Zhang Q. Can metal-nitrogen-carbon catalysts satisfy oxygen electrochemistry? J Mater Chem A, 2016, 4: 4998-5001

16 Wang XR, Liu JY, Liu ZW, et al. Identifying the key role of pyridinic-N-Co bonding in synergistic electrocatalysis for reversible ORR/OER. Adv Mater, 2018, 30: 1800005

17 Zhao $\mathrm{H}$, Sun $\mathrm{C}$, Jin $\mathrm{Z}$, et al. Carbon for the oxygen reduction reaction: a defect mechanism. J Mater Chem A, 2015, 3: 1173611739

18 Wang Q, Shang L, Shi R, et al. NiFe layered double hydroxide nanoparticles on $\mathrm{Co}, \mathrm{N}$-codoped carbon nanoframes as efficient bifunctional catalysts for rechargeable zinc-air batteries. Adv Energy Mater, 2017, 7: 1700467

19 Wang A, Li J, Zhang T. Heterogeneous single-atom catalysis. Nat Rev Chem, 2018, 2: 65-81

20 Zhang D, Chen W, Li Z, et al. Isolated Fe and Co dual active sites on nitrogen-doped carbon for a highly efficient oxygen reduction reaction. Chem Commun, 2018, 54: 4274-4277

21 Zhang G, Jia $\mathrm{Y}$, Zhang $\mathrm{C}$, et al. A general route via formamide condensation to prepare atomically dispersed metal-nitrogencarbon electrocatalysts for energy technologies. Energy Environ Sci, 2019, 12: 1317-1325

22 Li H, Ma L, Han C, et al. Advanced rechargeable zinc-based batteries: Recent progress and future perspectives. Nano Energy, 2019, 
62: $550-587$

23 Tian W, Li H, Qin B, et al. Tuning the wettability of carbon nanotube arrays for efficient bifunctional catalysts and $\mathrm{Zn}$-air batteries. J Mater Chem A, 2017, 5: 7103-7110

$24 \mathrm{Xu} \mathrm{W}, \mathrm{Lu} \mathrm{Z}$, Zhang $\mathrm{T}$, et al. An advanced zinc air battery with nanostructured superwetting electrodes. Energy Storage Mater, 2019, 17: 358-365

25 Yin $\mathrm{P}, \mathrm{Yao} \mathrm{T}, \mathrm{Wu} \mathrm{Y}$, et al. Single cobalt atoms with precise Ncoordination as superior oxygen reduction reaction catalysts. Angew Chem Int Ed, 2016, 55: 10800-10805

$26 \mathrm{Lu} \mathrm{Z,Xu} \mathrm{W,} \mathrm{Zhu} \mathrm{W,} \mathrm{et} \mathrm{al.} \mathrm{Three-dimensional} \mathrm{NiFe} \mathrm{layered} \mathrm{double}$ hydroxide film for high-efficiency oxygen evolution reaction. Chem Commun, 2014, 50: 6479-6482

27 Li Y, Dai H. Recent advances in zinc-air batteries. Chem Soc Rev, 2014, 43: 5257-5275

28 Wang HF, Tang C, Zhang Q. A review of precious-metal-free bifunctional oxygen electrocatalysts: rational design and applications in Zn-air batteries. Adv Funct Mater, 2018, 28: 1803329

29 Gong M, Dai H. A mini review of NiFe-based materials as highly active oxygen evolution reaction electrocatalysts. Nano Res, 2015, 8: 23-39

30 Meng FL, Liu KH, Zhang Y, et al. Recent advances toward the rational design of efficient bifunctional air electrodes for rechargeable Zn-air batteries. Small, 2018, 14: 1703843

31 Tang C, Wang HS, Wang HF, et al. Spatially confined hybridization of nanometer-sized $\mathrm{NiFe}$ hydroxides into nitrogen-doped graphene frameworks leading to superior oxygen evolution reactivity. Adv Mater, 2015, 27: 4516-4522

32 Xue X, Yu F, Peng B, et al. One-step synthesis of nickel-iron layered double hydroxides with tungstate acid anions via flash nano-precipitation for the oxygen evolution reaction. Sustain Energy Fuels, 2019, 3: 237-244

33 Zhou D, Cai Z, Lei X, et al. NiCoFe-layered double hydroxides/Ndoped graphene oxide array colloid composite as an efficient bifunctional catalyst for oxygen electrocatalytic reactions. Adv Energy Mater, 2018, 8: 1701905

34 Zhu X, Tang C, Wang HF, et al. Dual-sized NiFe layered double hydroxides in situ grown on oxygen-decorated self-dispersal nanocarbon as enhanced water oxidation catalysts. J Mater Chem A, 2015, 3: 24540-24546

35 Feynman RP. There's plenty of room at the bottom. J Microelectromech Syst, 1992, 1: 60-66

36 Wang W, Liu Y, Li J, et al. NiFe LDH nanodots anchored on 3D macro/mesoporous carbon as a high-performance ORR/OER bifunctional electrocatalyst. J Mater Chem A, 2018, 6: 14299-14306

37 Jiang $\mathrm{H}, \mathrm{Gu}$ J, Zheng X, et al. Defect-rich and ultrathin $\mathrm{N}$ doped carbon nanosheets as advanced trifunctional metal-free electrocatalysts for the ORR, OER and HER. Energy Environ Sci, 2019, 12: 322-333

38 Su CY, Cheng H, Li W, et al. Atomic modulation of FeCo-nitrogen-carbon bifunctional oxygen electrodes for rechargeable and flexible all-solid-state zinc-air battery. Adv Energy Mater, 2017, 7: 1602420

39 Fu G, Liu Y, Chen Y, et al. Robust N-doped carbon aerogels strongly coupled with iron-cobalt particles as efficient bifunctional catalysts for rechargeable $\mathrm{Zn}$-air batteries. Nanoscale, 2018, 10: 19937-19944

40 Wang HF, Tang C, Zhu X, et al. A 'point-line-point' hybrid electrocatalyst for bi-functional catalysis of oxygen evolution and reduction reactions. J Mater Chem A, 2016, 4: 3379-3385
41 Tan H, Tang J, Henzie J, et al. Assembly of hollow carbon nanospheres on graphene nanosheets and creation of iron-nitrogendoped porous carbon for oxygen reduction. ACS Nano, 2018, 12: 5674-5683

42 Li S, Cheng C, Zhao X, et al. Active salt/silica-templated 2D mesoporous $\mathrm{FeCo}-\mathrm{N}_{x}$-carbon as bifunctional oxygen electrodes for zinc-air batteries. Angew Chem Int Ed, 2018, 57: 1856-1862

43 Qian L, Lu Z, Xu T, et al. Trinary layered double hydroxides as high-performance bifunctional materials for oxygen electrocatalysis. Adv Energy Mater, 2015, 5: 1500245

$44 \mathrm{Xu} \mathrm{W,} \mathrm{Lu} \mathrm{Z,} \mathrm{Sun} \mathrm{X,} \mathrm{et} \mathrm{al.} \mathrm{Superwetting} \mathrm{electrodes} \mathrm{for} \mathrm{gas-involving}$ electrocatalysis. Acc Chem Res, 2018, 51: 1590-1598

45 Li Y, Zhang $\mathrm{H}$, Han $\mathrm{N}$, et al. Janus electrode with simultaneous management on gas and liquid transport for boosting oxygen reduction reaction. Nano Res, 2019, 12: 177-182

46 Lu Z, Xu W, Ma J, et al. Superaerophilic carbon-nanotube-array electrode for high-performance oxygen reduction reaction. Adv Mater, 2016, 28: 7155-7161

47 Lu Z, Li Y, Lei X, et al. Nanoarray based "superaerophobic" surfaces for gas evolution reaction electrodes. Mater Horiz, 2015, 2: 294-298

48 Chen B, He X, Yin F, et al. MO-Co@N-doped carbon (M = Zn or $\mathrm{Co}$ ): Vital roles of inactive $\mathrm{Zn}$ and highly efficient activity toward oxygen reduction/evolution reactions for rechargeable $\mathrm{Zn}$-air battery. Adv Funct Mater, 2017, 27: 1700795

49 Dresp S, Luo F, Schmack R, et al. An efficient bifunctional twocomponent catalyst for oxygen reduction and oxygen evolution in reversible fuel cells, electrolyzers and rechargeable air electrodes. Energy Environ Sci, 2016, 9: 2020-2024

50 Fu S, Zhu C, Su D, et al. Porous carbon-hosted atomically dispersed iron-nitrogen moiety as enhanced electrocatalysts for oxygen reduction reaction in a wide range of $\mathrm{pH}$. Small, 2018, 14: 1703118

51 Zhang W, Yao X, Zhou S, et al. ZIF-8/ZIF-67-derived Co- $\mathrm{N}_{x}$ embedded 1D porous carbon nanofibers with graphitic carbonencased Co nanoparticles as an efficient bifunctional electrocatalyst. Small, 2018, 14: 1800423

52 Treimer S, Tang A, Johnson DC. A consideration of the application of Koutecký-Levich plots in the diagnoses of charge-transfer mechanisms at rotated disk electrodes. Electroanalysis, 2002, 14: 165-171

53 Ibraheem S, Chen S, Li J, et al. In situ growth of vertically aligned FeCoOOH-nanosheets/nanoflowers on Fe, $\mathrm{N}$ co-doped 3D-porous carbon as efficient bifunctional electrocatalysts for rechargeable zinc- $\mathrm{O}_{2}$ batteries. J Mater Chem A, 2019, 7: 9497-9502

54 Zhang $\mathrm{C}$, Zhang G, Li H, et al. Interfacial dehalogenation-enabled hollow N-doped carbon network as bifunctional catalysts for rechargeable Zn-air battery. Electrochim Acta, 2017, 247: 1044-1051

55 Jiang Y, Song Y, Li Y, et al. Charge transfer in ultrafine LDH nanosheets/graphene interface with superior capacitive energy storage performance. ACS Appl Mater Interfaces, 2017, 9: 3764537654

56 Zhang J, Liu J, Xi L, et al. Single-atom Au/NiFe layered double hydroxide electrocatalyst: probing the origin of activity for oxygen evolution reaction. J Am Chem Soc, 2018, 140: 3876-3879

57 Li D, Hao G, Guo W, et al. Highly efficient Ni nanotube arrays and $\mathrm{Ni}$ nanotube arrays coupled with $\mathrm{NiFe}$ layered-double-hydroxide electrocatalysts for overall water splitting. J Power Sources, 2020, 448: 227434

58 Zhang J, Zhang M, Qiu L, et al. Three-dimensional interconnected 
core-shell networks with $\mathrm{Ni}(\mathrm{Fe}) \mathrm{OOH}$ and $\mathrm{M}-\mathrm{N}-\mathrm{C}$ active species together as high-efficiency oxygen catalysts for rechargeable $\mathrm{Zn}$-air batteries. J Mater Chem A, 2019, 7: 19045-19059

Acknowledgements This work was financially supported by the National Natural Science Foundation of China (21701101), the National Key Research and Development Project, Key Projects of Intergovernmental International Innovation Cooperation (2018YFE0118200 and 2016YFF0204402), the Fundamental Research Funds for the Central Universities (18CX06063A), the Key Research and Development Project of Shandong Province (2019JZZY010506), the Scientific Research Awards Foundation for Outstanding Young Scientists of Shandong Province (ZR2018JL010), the Joint Fund of Outstanding Young Talents of Shandong Province (ZR2017BB018), and the Program of Qingdao Scientific and Technological Innovation High-level Talents Project (172-1-1-zhc).

Author contributions Wang $\mathrm{Y}$ and Zhang $\mathrm{G}$ designed and engineered the samples; Wang Y, Ma M, and Ma Y performed the experiments; Huang J, Chen $\mathrm{C}$ and Zhang $\mathrm{Y}$ helped analyze and discuss the data; Wang $Y$ and Zhang $G$ wrote and revised the paper with support from Sun $\mathrm{X}$ and Yan $\mathrm{Z}$. All authors contributed to the general discussion.

Conflict of interest The authors declare no conflict of interest.

Supplementary information

Supporting data are available in the online version of the paper.

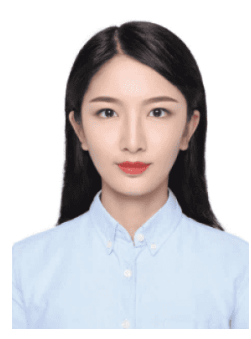

Yiyan Wang is currently a $\mathrm{PhD}$ candidate at China University of Petroleum (East China). Her research interests focus on the carbon-based nanomaterials for ORR/OER electrocatalysts and Zn-air battery.

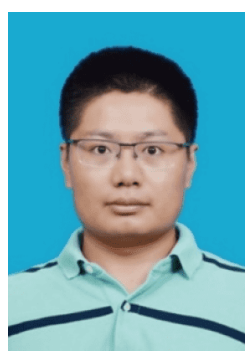

Guoxin Zhang received his BSc degree in 2010 and $\mathrm{PhD}$ degree in 2016 from Beijing University of Chemical Technology. He is an associate professor at Shandong University of Science and Technology. His interests focus on the controllable fabrication of carbon nanomaterials with atomic dopants of non-metal or non-precious metal elements and their applications in electrochemical energy conversion and storage.

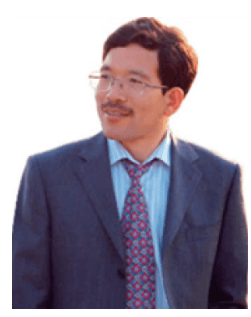

Zifeng Yan received his BSc degree in 1988 and MSc degree in 1991 from Lanzhou University, China. In 1999, he received his $\mathrm{PhD}$ degree from Lanzhou Institute of Chemical Physics, Chinese Academy of Sciences. He is a full professor at China University of Petroleum (East China). His interests focus on the catalytic materials and catalysts, nano-catalysis technology, new carbon materials and new energy technology.

\section{超小 NiFe水滑石耦合单原子FeCo-NC纳米花用于 可充电锌空气电池}

王一棪 ${ }^{1}$, 张国新 ${ }^{2 *}$, 马莽 ${ }^{1}$, 马岩 ${ }^{1}$, 黄剑坤 ${ }^{1}$, 陈晨 ${ }^{1}$, 张颖 ${ }^{1}$, 孙晓明 ${ }^{1}$, 阎子峰 ${ }^{1 *}$

摘要 单原子分散的FeCo-NC材料, 具有特殊的花状结构和原子级 分散 $\mathrm{Fe} / \mathrm{Co}$ 位点, 适用于可控沉积超小 $\mathrm{NiFe}$ 水滑石纳米点 $(\mathrm{NiFe}$ $\mathrm{ND})$, 从而制备具有优异氧还原(ORR)和氧析出(OER)性能的双功 能催化材料. FeCo-NC材料本身具有三维立体花状介孔结构和丰 富的 N/O功能位点, 可以实现对 NiFe-ND尺寸的有效控制(直径约 $4 \mathrm{~nm}$ ), 使得制备的特殊复合材料的 OER和ORR活性位暴露度达最 大值. 电化学测试表明在 $0.1 \mathrm{~mol} \mathrm{~L}^{-1} \mathrm{KOH}$ 电解液中 $\mathrm{NiFe}-\mathrm{ND}$ / $\mathrm{FeCo}-\mathrm{NC}$ 的 $\mathrm{ORR}$ 半波电势为 $0.85 \mathrm{~V}$, 当电流密度为 $10 \mathrm{~mA} \mathrm{~cm}$ 时的 OER电势为 $1.66 \mathrm{~V}$. 原位拉曼结果进一步证实了 $\mathrm{NiFe}-\mathrm{ND} / \mathrm{FeCo}-\mathrm{NC}$ 材料优良的OER活性来源于电化学过程中产生的丰富 $\mathrm{Ni}(\mathrm{Fe}) \mathrm{OOH}$ 活性相. 采用 $\mathrm{NiFe}-\mathrm{ND} / \mathrm{FeCo}-\mathrm{NC}$ 组装的锌空气电池具有较小的充 放电电压差 $\left(0.87 \mathrm{~V}, 20 \mathrm{~m} \mathrm{~A} \mathrm{~cm}^{-2}\right)$ 和持久的循环稳定性. 同时, $\mathrm{NiFe}-\mathrm{ND} / \mathrm{FeCo}-\mathrm{NC}$ 也可以应用于全固态锌空气电池, 即使在形变 的情况下仍然具有良好的循环稳定性. 本工作可为单原子金属氮 碳催化剂作为特殊基底材料应用于新型多功能催化剂的研发提供 指导. 